bringing together from many parts of the world the most outstanding investigators currently active in research on various aspects pertinent to the general subject.

At the beginning, the editors make some apposite remarks, for example, to the effect that although the symposium papers make it evident that pressure is as important an influence as temperature on the lives of many (especially marine) aquatic organisms, the literature on pressure is much less than that on temperature. This observation is underscored by the fact that, within the last almost 100 years, this is only the third book to be published dealing primarily with the biological effects of increased pressure: the first was by P. Regnard in 1891 and the second, edited by A. M. Zimmerman, appeared as recently as 1970.

In their introductory remarks the editors seem to take too restricted a view in the statement that "The fundamental effect of pressure is to favour changes that involve a reduction in volume; ...", whereas it is certainly true that a no less fundamental effect of pressure is to oppose changes that involve an increase in volume, inasmuch as both sorts of changes may assume critical importance in reactions involving large molecules such as the enzymes or other proteins and the nucleic acids characteristic of biological systems. Further, equally fundamental aspects of the effects of pressure are that the net result, in regard to the magnitude and the direction, that is, inhibition or stimulation, can be determined (1) by temperature, and (2) at a given temperature, by the chemical environment, for example, as in the reversal of narcosis by increased hýdrostatic pressure. Although such relationships were revealed and interpreted with some success with the aid of the theory of absolute reaction rates more than a generation ago, they are not taken into account in various instances wherein they might seem useful in arriving at a clearer understanding of the phenomena involved, and, for the most part, they are only vaguely or casually mentioned in the symposium papers.

The broadly inclusive and indeed highly informative treatment of the subject conveys something of an impression that the observed results of experiments are generally due to pressure per se, whereas different conditions and different ranges of pressure require different avenues of theoretical interpretation. For example, increased pressures will increase or decrease the rate of a chemical reaction in homogeneous solution in accordance with the amount of pressure and the molecular volume change involved in forma. tion of the activated (transition) states from the reactants. A volume change of this sort is never great enough to be measurable by comparing reaction rates at atmospheric and below-atmospheric pressure. When a gas phase is present, however, as in air-breathing animals, changes in pressure in either direction, that is, to greater or less than one atmosphere, are accompaniegd by changes in concentration of reactants, thereby introducing added complications, for example, in the physiology of diving mammals and of man in space. Additional complications arise in a deformation type of pressure rather than a uniformly acting, hydrostatic type.

Manifold opportunities for fruitful research are evident in this book, notably studies on animals indigenous to the deep sea, a type of study which Regnard did not significantly achieve and which is only now being seriously undertaken by some of the authors represented in the book.

For a number of reasons, this symposium volume may be considered indispensable to anyone interested in the general subject. Frank H. JOHNSON.

\section{Physics in Archaeology}

Methods of Physical Examination in Archaeology. By M. S. Tite. Pp. xxx+ 389. (Seminar: New York and London, February 1973.) $£ 6.80$.

IN recent years the application of physical methods to archaeology has grown in importance. It is true that numerous fascinating methods have long been available, but because of lack of resources or entrenched archaeological attitudes, they have been comparatively little used. The situation is now changing, however; the scientist's enthusiasm for devising ever more refined methods is being matched by their application to archaeological problems, and the tendency to appoint scientists to the staffs of university archaeology departments in helping to promote the integration of these techniques as part of the accepted methodology in the study of the past. The time is now ripe for a handbook on the subject and this is admirably provided by Dr. Tite's Methods of Physical Examination.

The book covers a broad spectrum: techniques for locating archaeological sites, age determination and methods for analysing the composition of artefacts. Within each of these fields, Dr Tite carefully and lucidly describes nearly all the methods of proven value, including very recent developments, and in each case he gives useful examples showing how the techniques have been applied in archaeology. Most of the information has been culled from the existing literature and there is little that is new, but this is no criticism, for it is most useful to have this body of information under the same cover for the first time. If the archaeologist wishes to know what work has been done on, for example, the characterization of a certain type of artefact or if he wishes to discover what method would best solve a particular problem, Dr Tite's book will provide a ready and authoritative answer.

The work has been carefully prepared and thus there are few points to criticize, though I could not help noting that one of my suggestions had been inadvertently attributed to another worker! The choice of plates is, however, somewhat strange, for many show little of interest or serve no useful purpose. For example, Plate 1, of the Overton Down experimental earthwork, receives only passing mention in the introduction; Plate 7 of excavated pits and ditches at South Cadbury shows nothing that is not better illustrated in Fig. 18; while no less than two plates are devoted to the weathering laminae in ancient glass, which, as Dr Tite himself remarks, are of dubious value in dating. One has the impression that the author was trying to meet his publisher's demand for twenty-five plates, but with a little imagination these could have been much more instructive.

These criticisms are dwarfed, however, by the overall value of the book. It should certainly have a place on the shelves of all archaeological scientists (whether they work in science or in archaeology departments) and it will also be very useful to many archaeologists. The book will serve as a much-needed undergraduate text for students with some scientific grounding, but the arts based man will find the scientific jargon and formulae rather formidable.

\section{P. S. Peacock}

\section{Invertebrate Vision}

Information Processing in the Visual Systems of Arthropods. Edited by $\mathbf{R}$. Wehner. Pp. xi+334. (Springer: Berlin and New York, 1973.) 36 DM ; $\$ 10.50$.

THIS book contains the papers given at a conference held in March 1972 on the arthropod visual system. The participants were mostly from Germany and Switzerland, and a few were from Britain. The contributions are, however, all in English which, it seems churlish to say, is not always easy to understand. The papers covered a wide range of topics, including the anatomy of the optic lobe, the optics of the compound eye, pigment biochemistry, colour vision, pattern recognition, and orientation behaviour.

The stated intention of the book is to provide a summary of recent work on the arthropod visual system for people in a variety of fields, and particularly 